\title{
Lyophilised dura mater: experimental implantation and extended clinical neurosurgical use
}

\author{
$M$. R. MACF A R L A NE A N D L S YMON \\ From the Department of Neurosurgical Studies, The National Hospital For Nervous Diseases, London
}

SUMMARY The historical development of dural substitutes and the process of regeneration of dura mater are reviewed. Lyophilised human cadaver dura mater has been implanted intracranially in baboons and the graft shown to be incorporated with vascularisation but with ossification. In the human, lyophilised dura mater used as a dural substitute also becomes a viable tissue but without ossification. A retrospective study of its use in 100 neurosurgical patients showed a low complication rate and it is suggested that there are occasions when the ready availability of lyophilised dura mater, without the need for a further incision, makes it the dural substitute of choice.

Interest in the reconstitution of dural defects dates from Beach (1890), who suggested the use of gold foil for the prevention of meningocerebral adhesions. The first report on the clinical implantation of a dural substitute, rubber tissue, was by Abbe (1895). Many materials have been used as dural substitutes from 1895 to 1954, when Campbell et al. (1958), first used freeze-dried, vacuumstored human dura mater.

The process of regeneration of dural defects in the absence of any graft was investigated by Lear and Harvey (1924), Penfield (1924), and Glasser and Thienes (1938). Trotter (1924) observed that if a segment of cerebral dura mater was excised and the overlying scalp left in contact with the brain, a neomembrane would form which would be indistinguishable from the old dura mater within a few weeks. Keener (1959) fully reviewed the literature on dural regeneration and dural substitutes.

The necessity of formally closing a dural defect by inserting a dural substitute is open to question. One extreme, based on experimental and clinical evidence, is that as a neodural layer forms in the absence of a graft there is no indication for inserting a graft. The other extreme (Abbott and Dupree, 1971) is that the subdural space should be closed even after neurosurgical procedures in which dural removal has been necessary.

\footnotetext{
Address for reprint requests: Mr M. R. MacFarlane, Regional Neurological Centre, Newcastle General Hospital, Westgate Road, Newcastle upon Tyne NE4 6BE.

Accepted 27 February 1979
}

The indications for dural grafting as stated byo Abbott and Dupree (1970) were: the need tō $A$ close a meningeal defect in order to seal the $\vec{\oplus}$ 의

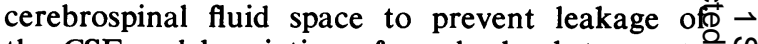
the CSF and herniation of cerebral substance; to $\$$ exclude contamination or infection in the wound and to minimise cortical scarring and adhesiong formation.

One of the more widely used dural substitutes in recent years is lyophilised human cadaver dura mater. Recent reports by Abbott and Dupree (1971) and Rosomoff and Malinin (1976) indicate an acceptably low complication rate.

We do not advocate the routine formal reconstitution of all dural defects, but will show that there is sound experimental and clinical evidence to attest to the efficacy with which lyophilised dura mater may be used as a dural substitute.

Sayad and Harvey (1923) recorded the first experimental study concerned primarily with regeneration of dura mater. Rosomoff (1959) reported the results of implantation in dogs, of fresh autogenous dura mater, and lyophilised canine and human dura mater. A cortical injury was administered to alternate animals. The histological appearances of all grafts were described as showing scattered areas of round-cell accumulations with or without calcification. The human dura mater evoked a more prominent round cell inflammatory reaction and also calcification. There was infiltration of the grafts by fibroblasts and also evidence of vascularisation. No foreign body giant cells were found except in relation to 
sutures. The underlying brain in dogs without cortical injury showed no untoward reaction. The degree of adhesions in the cortical-injured dogs did not differ with the type of graft.

\section{Experimental materials and methods}

In 1969 we conducted a trial to examine the histological changes associated with the implantation of lyophilised human cadaver dura mater in baboons, using Lyodura prepared commercially by B. Braun Melsungun AG. The preparation of Lyodura involves lyophilisation of cleaned human cadaver dura mater followed by gamma ray sterilisation.

In six cynomologous baboons under general endotracheal anaesthesia, convexity craniotomies were performed and the dura mater excised leaving leptomeninges and cortex intact. Lyophilised dura mater was then implanted and sutured around the periphery with interrupted black silk sutures. In all, the bone flap was replaced and scalp closed. The baboons were killed in the course of other unrelated experimental procedures some 12 months later.

\section{Experimental results}

Microscopic examination showed no adhesion formation between cortex, leptomeninges, or dura mater. Microscopic examination of the lyophilised dura mater showed fibroblastic infiltration of the dural collagenous framework. Areas of prominent fibroblastic infiltration also showed vascularisation. There were occasional accumulations of round cells. Ossification with bone formation and occasional osteoblasts was a prominent feature within the lyophilised dura mater (Fig. 1). The only regions showing a foreign body reaction with polymorphonuclear round cells and foreign body giant cells were those associated with silk sutures. There was occasionally a mild degree of round and polymorphonuclear cell infiltration of the leptomeninges. No significant changes were seen in the underlying cortex or white matter (Fig. 2).

\section{Clinical materials and methods}

Lyophilised dural grafts (using Lyodura) were inserted in 100 patients over the 10 year period from 1968 to 1978 . The minimum follow-up period was five months.

The size of lyophilised dural grafts in our series ranged from 4 to 100 square centimetres. The techniques of fixation of the grafts to host dura mater varied: 52 by peripheral "tacking" sutures of black silk, usually in sufficient quantity only to hold the graft in position, making no attempt at achieving a watertight seal; five by continuous silk suture; three with Histoacryl Blau; four with

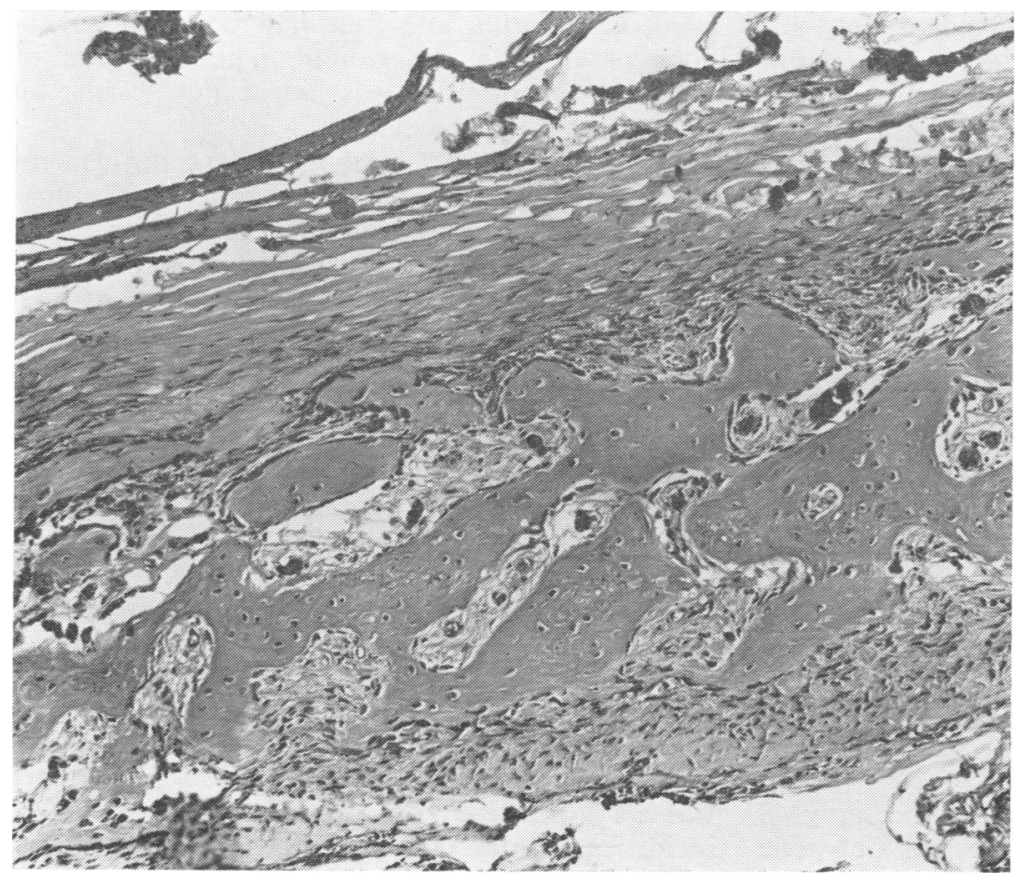

Fig. 1 Lyophilised dura mater implanted in the baboon, showing fibroblastic infiltration, vascularisation, and ossification. 


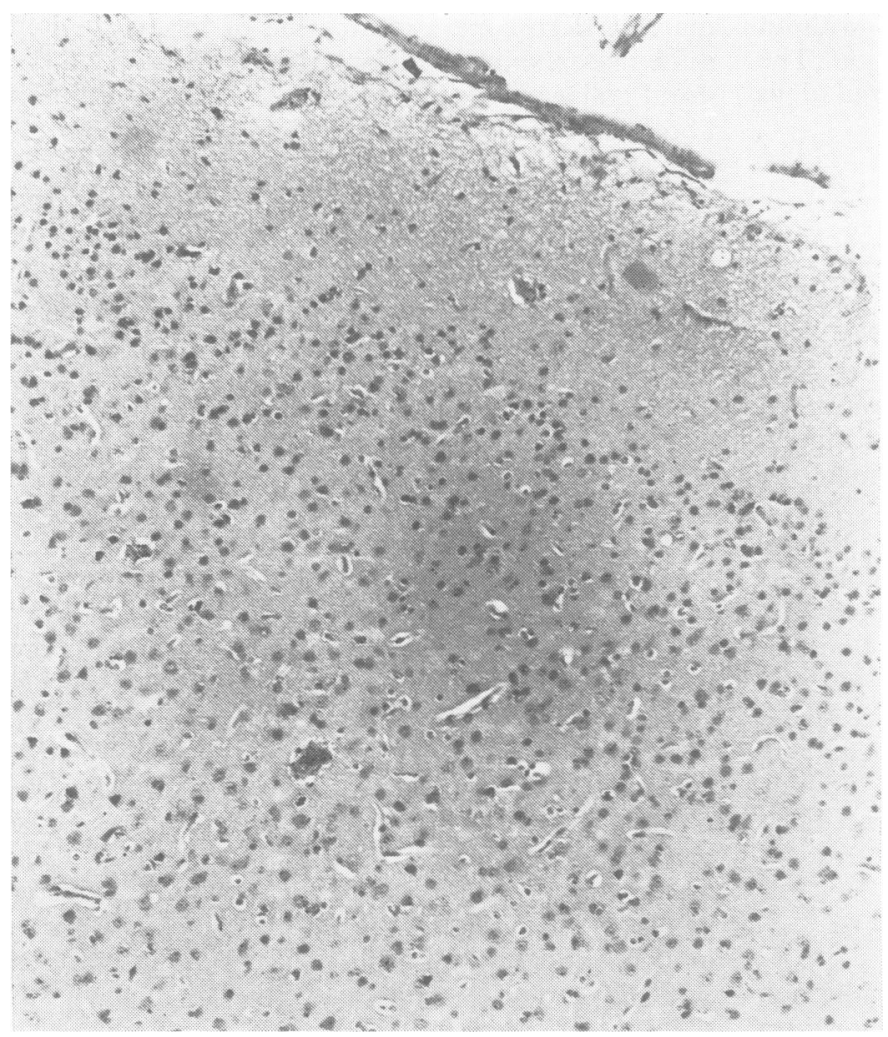

Fig. 2 Section of baboon brain underlying lyophilised dura mater.

tantalum clips; 24 were not fixed but merely applied as onlay grafts, usually held by overlying oxidised cellulose or gelfoam. In 12 patients, the method of fixation was not recorded.

Wound closure in the majority was with silk to all layers, the exceptions being lumbar spinal cases, these being closed with chromic catgut. Wound drainage by suction drain was used in the majority of cases.

Antibiotics were not used on a prophylactic basis, their use being restricted to patients with evidence of wound infection, meningitis, or coincidental pulmonary or urinary infection. Steroid therapy was restricted to a small minority preoperatively but the majority of cases received steroids postoperatively.

\section{Clinical results}

For the purposes of analysis, the patients have been grouped into four categories according to type of operative procedure (Table).

Of the 56 patients undergoing laminectomy 48 were free of complications. There was only one frank CSF fistula and four had transient collecto tions of CSF in the wound. The one case of bacterial meningitis was associated with an established meningocoele.

Eighteen of the 22 patients undergoing decompression of the foramen magnum and upper cervical laminectomies for cerebellar ectopia, with or without syringomyelia, were without complications. There were two cases with transient CSF collections and one case each of aseptic and bacterial meningitis.

Of the 15 patients undergoing craniotomy for meningioma, only one developed a CSF leak. This consisted of a single episode of CSF rhinorrhoea three months after operation and it resolved spontaneously. In this series only two craniotomies were performed for elective cure of CSF rhinorrhoea, both being successful, and the remaining five miscellaneous craniotomies were without complication.

Thus in overall analysis, $87 \%$ were free from complications. Eight patients $(8 \%)$ had a CSF leak but only one required further surgery. There was a $1 \%$ incidence of wound infection and a $2 \%$ incidence each of aseptic and bacterial meningitis. 
Table Analysis of 100 neurosurgical patients with implanted lyophilised dura mater

\begin{tabular}{|c|c|c|c|c|c|c|c|}
\hline \multirow[t]{3}{*}{ Operative procedure } & \multirow{3}{*}{$\begin{array}{l}\text { Complication } \\
\text { free }\end{array}$} & \multicolumn{5}{|c|}{ Complications } & \multirow[t]{3}{*}{ Total } \\
\hline & & \multicolumn{2}{|l|}{ CSF leak } & \multirow{2}{*}{$\begin{array}{l}\text { Wound } \\
\text { infection }\end{array}$} & \multicolumn{2}{|c|}{ Meningitis } & \\
\hline & & Fistula & $\begin{array}{l}\text { Transient } \\
\text { CSF collection }\end{array}$ & & Aseptic & Bacterial & \\
\hline Spinal & 48 & 1 & 4 & 1 & 1 & 1 & 56 \\
\hline $\begin{array}{l}\text { Foramen magnum decompression and } \\
\text { upper cervical laminectomy for cerebellar } \\
\text { ectopia and syringomyelia }\end{array}$ & 18 & 0 & 2 & 0 & 1 & 1 & 22 \\
\hline $\begin{array}{l}\text { Craniotomy for meningioma, } \\
14 \text { supratentorial (mainly sphenoid ridge) } \\
1 \text { infratentorial }\end{array}$ & 14 & $\begin{array}{l}1 \text { (transient } \\
\text { rhinorrhoea) }\end{array}$ & & 0 & 0 & & 15 \\
\hline $\begin{array}{l}\text { Craniotomy (miscellaneous) } 2 \text { for CSF } \\
\text { rhinorrhoea, } 5 \text { others }\end{array}$ & 7 & 0 & & 0 & 0 & & 7 \\
\hline Totals & 87 & & & 13 & & & 100 \\
\hline
\end{tabular}

\section{Histological features of lyophilised dural graft in the human}

The histology of implanted lyophilised dura mater in the human is well seen in one of the patients in this series. This patient had originally had exposure of the foramen magnum and high cervical spine for removal of a foramen magnum meningi- oma. A lyophilised dural graft had been inserted. Seven months later this patient was re-explored for biopsy of an intramedullary cervical glioma, and the lyophilised dural graft was partly excised. The graft appeared, macroscopically, to be a little thicker than "normal" dura mater and was vascularised. Microscopically (Fig. 3) the graft showed colonisation by fibroblasts and stem cells

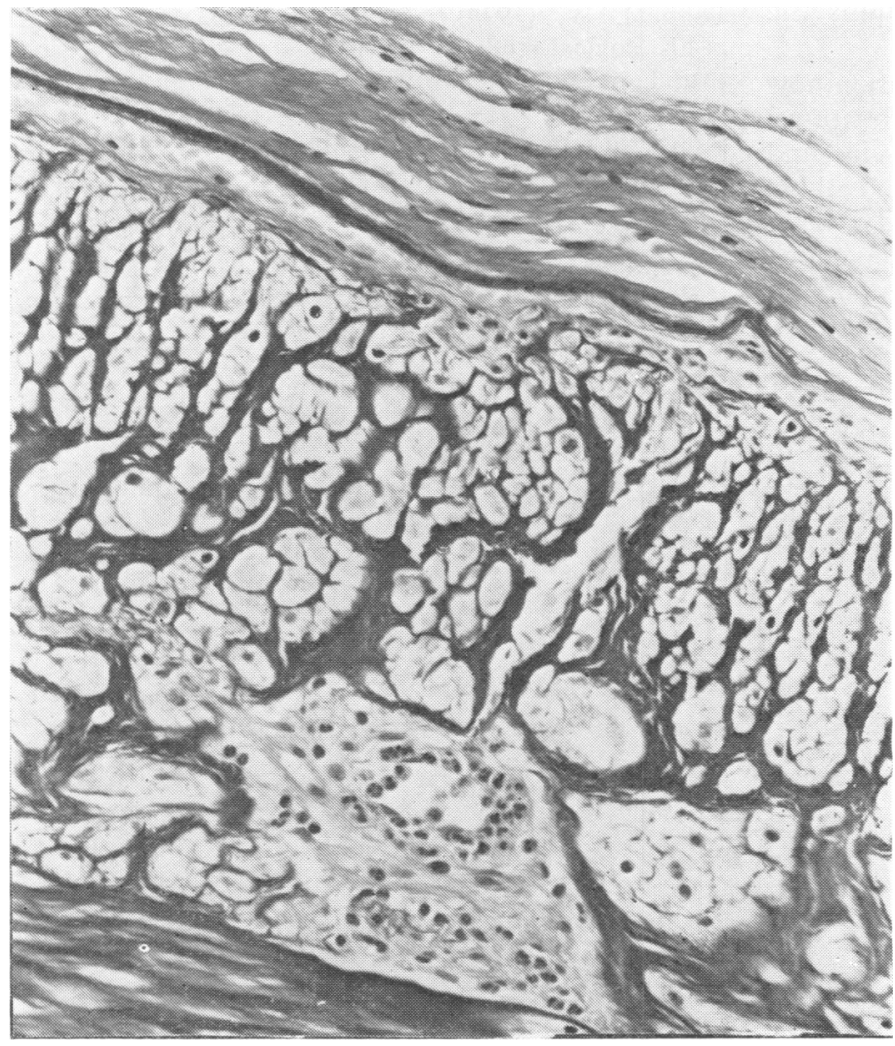

Fig. 3 Lyophilised dura mater implanted in a patient seven months previously, showing fibroblastic infiltration, vascularisation but no ossification. 
and well-formed blood vessels were prominent. There was no ossification, and ossification has not been reported in lyophilised dura mater implanted in the human.

\section{Discussion}

The experimental work with implantation of lyophilised human cadaver dura mater in dogs, and now in baboons, demonstrates that the graft is incorporated by fibroblastic infiltration and vascularisation, but with ossification. In humans, the lyophilised dura mater also becomes a viable tissue but without ossification.

The efficacy of any of the dural substitutes must be assessed with regard to five factors: (1) Does the graft result in restoration of a water-tight dural envelope? (2) Does the graft prevent ingress of extradural or superficial wound infection into CSF or brain? (3) Will the graft seal an established CSF fistula? (4) Is the use of the graft associated with an increased infection rate? (5) Is the graft readily obtainable?

The low complication rate in our 100 patierits indicates that lyophilised dura mater fulfils the first four of these criteria.

There would appear to be little justification now for using inorganic or synthetic dural substitutes. The use of pericranium, temporalis fascia, and fascia lata is justifiably widespread, and these materials have the advantage of "pliability" over lyophilised dura mater. There are situations, however, when the ready availability of lyophilised dura mater without the need for a further incision, renders it the dural substitute of choice.

Dr W. G. P. Mair, of the Department of Neuropathology, The National Hospital for Nervous Diseases, Queen Square, kindly undertook the histological preparations and examinations.

\section{References}

Abbe, R. (1895). Rubber tissue for meningeal adhesions. Transactions of the American Surgical Association, 13, 490-491.

Abbott, W. M., and Dupree E. L. (1970). The procurement, storage and transplantation of lyophilised human cadaver dura mater. Surgery, Gynecology and Obstetrics, 130, 112-118.

Abbott, W. M., and Dupree, E. L. (1971). Clinical results of lyophilised human cadaver dura transplantation. Journal of Neurosurgery, 34, 770-773.

Beach, H. H. A. (1890). Compound comminuted fracture of the skull; epilepsy for five years, operation, recovery. Boston Medical and Surgical Journal, 122, 313-315.

Campbell, J. B., Bassett, C. A. L., and Robertson, J. W. (1958). Clinical use of freeze-dried human dura mater. Journal of Neurosurgery, 15, 207-214.

Glaser, M. A., and Thienes, C. H. (1938). Dural defects: how important is their surgical repair? An experimental and clinical study upon heteroplastic and autoplastic dural grafts. California and Western Medicine, 48, 163-166.

Keener, E. B. (1959). Regeneration of dural defects. A review. Journal of Neurosurgery, 16, 415-423.

Lear, M., and Harvey, S. C. (1924). The regeneration of the meninges. The pia-arachnoid. Annals of Surgery, 80, 536-544.

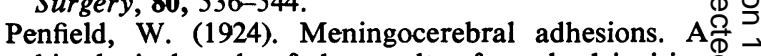
histological study of the results of cerebral incision 0 and cranioplasty. Surgery, Gynecology and $\mathrm{Ob}$ stetrics, 39, 803-810.

Rosomoff, H. L. (1959). Ethylene oxide sterilised, freeze-dried dura mater for the repair of pachymeningeal defects. Journal of Neurosurgery, 16, 197-208.

Rosomoff, H. L., and Malinin, T. I. (1976). Freezedried allografts of dura mater-20 years' experience. Transplantation Proceedings, VIII, No. 2, Supplement 1, 133-138.

Sayad, W. Y., and Harvey, S. C. (1923). The regeneration of the meninges. The dura mater. Annals of Surgery, 77, 129-141.

Trotter, W. (1924). A lecture on the sensibility of the skin in relation to neurological theory. Lancet, 1 , 252-263. 